\title{
New Thoughts on the Colleges and Universities Implementing the Warm Power Strategy
}

\author{
Qizhen Yang \\ Huaiyin Normal University \\ Huaian, China 223000
}

\author{
Hui Wang \\ Huaiyin Normal University \\ Huaian, China 223000
}

\author{
Linghong Nie \\ Huaiyin Normal University \\ Huaian, China 223000
}

\begin{abstract}
Based on the connotation of warm power, in view of the chaos of "hard power and soft power" in colleges and universities, it is important to use warm power and advocate the goodwill for the colleges and universities in the context of new media. On the basis of mutual understanding and mutual trust, colleges and universities should sublimate human attitudes and measures to deepen the emotional exchanges among people, individuals and organizations and groups, eliminate barriers and guards, construct a fair, just, harmonious and happy college environment, build a positive atmosphere, unite manpower, and seek the development of education.
\end{abstract}

Keywords - comprehensive strength of colleges; warm power; hard power; soft power; warm power strategy

\section{INTRODUCTION}

Warm power is a new concept put forward in recent years. Wang Shanping [1] and Zuo Junzhan [2], [3] proposed the concept of warm power from the national and military levels, and discussed how to strengthen the warmth power to enhance the comprehensive strength of the country and the military, so that the country and the military can influence and take the initiative in the international competition arena, gain more state support and understanding in development, and achieve mutual benefit and win-win sharing. In the process of development, colleges and universities need to use the power of warm-heartedness and gain the understanding and support of teachers and students. Based on the concept and connotation of warm power, aiming at the current social and economic marketization, the popularization of college education, the diversification of colleges and universities, and the new situation of people's communication virtualization, it is very important to study on how to implement the strategy of warmth and strength, eliminating barriers and guards, creating a fair, just, harmonious and happy environment, establishing the concept of seeking common ground while reserving differences. With the attitude and measures of warming people and sublimating humanity, it will also be important to deepen the exchange of feelings between people, individuals and organizations and groups to promote the development of education in colleges and universities.

\section{THE PROPOSAL AND CONNOTATION OF "WARM POWER"}

\section{A. Proposal of "Warm Power"}

Warm power is a new concept put forward in recent years. In 2013, Wang Shanping [1] proposed a "warm power" strategy from China's response to the "smart power" strategy of the United States, and made the elaboration. The so-called "warm power" refers to the power eliminating the discrimination, resolving contradictions, breaking monopolies, restricting privileges, removing barriers, filling gaps, optimizing allocation, promoting harmonious symbiosis and national republic, warming people, and sublimating humanity. In 2014 and 2016, Zuo Junzhan [2], [3] made two papers, namely, "The spread of 'warm power': a new strategic thinking that should be established in military external propaganda under the new media environment" and "Using 'warm power' to spread and enhance the influence of military external communication". He respectively made a discussion on "how to use warm power to spread and enhance the influence of military external communication", and pointed out that "the virtue originated from the cooperation of human beings", and the communication of 'warm power' was based on human natural rationality, natural nature and natural justice. It was also an important concept of practicing and spreading the "Chinese Dream" to melt the barriers, expand exchanges, enhance cooperation, and promote mutual benefit and win-win innovation.

Based on the comments of warm power of Wang Shanping and Zuo Junzhan, warm power is a kind of warm and touching force that someone, an organization or something shows. It reflects the main theme of society. What it passed is a positive energy to promote the social reverence and goodness. Its essence is to have active measures, such as eliminating discrimination, breaking monopoly, restricting privilege, removing barriers and making up for the gap, to pursue the fair, just, harmonious, civilized and human 
freedom and all-round development, and promote the information dissemination activities of peaceful symbiosis, national republic, warming people, human sublimation and mutual understanding of civilization.

\section{B. The Connotation and Scope of Warm Power}

In different fields, warm power can be divided into the following categories: the ability to break the estrangement of ethnicity, gender, rank, party, region, and household registration to break the monopoly of power, namely, "political warm power"; the ability to eliminate investment, development, production, circulation, distribution, consumption, employment, accumulation and other discrimination to break the monopoly of wealth, namely, "economic warm power"; and the ability to dismantle religion, culture, art, science and technology, academic, education, public opinion barriers to break the knowledge monopoly, namely, "cultural warm power" [4]. In other words, whether it is a country or an organization, or an individual, it requires not only hard power and soft power, but also warm power. If the country has warm power, it will make people feel the warmth of society and have a sense of pride. If individuals have warm power, they will be affine and make the others feel the warmth, which is not only conducive to the construction of a harmonious and civilized society, but also can further enhance the cohesiveness and centripetal force of society, thus promoting the continuous development of society.

\section{HISTORICAL ORIGINS OF WARM POWER}

Although the warm power is a new concept that has only been in recent years, there are few documents related to the discussion of warm power, but it does not mean that there is no concrete manifestation of this in the past. Common sense tells that any new concept will basically not be fabricated out of thin air. If it really wants to trace it back, there are more or less the origins of history and reality behind each new concept. Scholars abstract and enhance the past ideas and phenomena into a new concept. The same goes for warm power. In 2013, Wang Shanping [1] pointed out in the article "Using 'warm power' thinking to response the 'smart power' of the United States": "warm power" has existed for thousands of years, and the talks among the prophets is due to the fact that the classical political struggle will not destroy the earth. Nowadays, it is also the trend of contemporary political struggle." In 2014, Zuo Junzhan [3] pointed out that the traditional cultural heritage and charm of the Chinese nation, which had been accumulated and condensed for thousands of years in China, was the resource and foundation of "warm power". With the thoughts, such as "harmony between man and nature", "the doctrine of the mean", "people-oriented concept" and "harmony among all nations", as well as its characteristics of unremitting self-improvement, social morality, thinking of danger in times of peace, contentment in heaven and upholding morality and justice, it once created a prosperous period of Chinese civilization attracting worldwide attention and continues to this day as "the only civilization in the world". Therefore, as large as a country, as small as a natural person, whether in internal affairs or in other fields, it can achieve a certain degree of echo with the warm power, and can also find a point of contact with the warm power.

Based on the historical origins of warm power, the country has the warm power of the country, and different countries have different warm power. Colleges and universities are part of society, bearing the burden of knowledge transfer, cultural education, cultural inheritance and civilization, shouldering the responsibility of delivering talents with all-round development of moral, intellectual, physical, aesthetics and labor education for the country. Therefore, in the new context of new media, the author makes a discussion on how to use the warm power to enhance the school's cohesiveness and centripetal force from the perspective of warm power, thereby enhancing the competitiveness of colleges and universities.

\section{THE INEVITABILITY OF COLLEGES AND UNIVERSITIES IMPLEMENTING THE STRATEGY OF WARM POWER}

\section{A. Calling for Warm Power: "the Will of the People Is the Most Powerful Political Force"}

Marxism points out that the people are the creators of history; the will of the people is the most powerful political force; the will of the people is stronger than the state's coercive power; and the will of the people determines the destiny of the country. In the critical period or at the critical moment, warm power is more able to gather people's wills and gather people's wisdom [5].

The construction and development of a university is a systematic and complex project. It requires the integration of system policies such as state policy support, university system support, school investment guarantee, teacher and student self-effort and cultural environment optimization, and promotes the development of schools in an all-round and three-dimensional manner. The business will be "effective", "orderly", "sentimental", and "righteous". The strength, influence and development potential of a university cannot be seen only by glamorous public propaganda, nor can it be based on blunt statistical data, or on tall buildings. It should focus on resolving contradictions, shaping the human environment and the comprehensive ability to "hold the group to warm up". The first three are tangible and hard powers that are easily perceived by ordinary people. The fourth one is invisible but externalized to tangible, as the great strategist Mao Zedong said: non-great wise people cannot grasp it. For example, in the author's university, the party and government leaders and the faculty and staff have a collective birthday, hold a birthday symposium, make dumplings with the teacher, sing a birthday song, eat a birthday cake, send a greeting card and take a group photo, and enjoy it every month. In the complicated teaching work of the school, the teacher's group birthday banquet is a drop in the waves, but in the hearts of teachers, it has caused waves of ripples. The teachers have left a message: thanks to the school; thanks to the leaders; loving Huaiyin Institute of Technology; and being grateful for the words and expressions, which greatly inspired the love for the university. What difficulty still can hold back the pace that 
the school advances for the collective that such passion struggles?

\section{B. Calling for the Warm Power of Colleges and Universities in the Era of Institutionalization, Normalization and Routinization}

1) In line with the era of college popularization, the "warm power" of colleges and universities is coming out: With the expansion of enrollment in colleges and universities in 1999, China's higher education has undergone fundamental changes. In 1999, the total number of students enrolled in higher education in China was 4,314,200 [6], and in 2018 it was 38.33 million [7]. The gross enrollment rate increased from $10.5 \%$ [6] in 1999 to $48.1 \%$ [7]. In 2019, Premier Li Keqiang pointed out in the government work report that in 2019 , the number of higher vocational education enrollment will increase by 1 million, and the gross enrollment rate of higher education in China will exceed $50 \%$. According to Martin Troll's standard of more than $15 \%$ [8], the popularity of higher education in China is an indisputable fact. Therefore, anything that rises and grows rapidly in a short period of time will inevitably lead to a decline in quality. Therefore, since China's higher education has entered mass education, it will inevitably bring new challenges of low quality while expanding in quantity. With the problems such as insufficient vitality, there still have a large gap compared with the needs of national development and the expectations of the people. With the development of the whole media society, social diversification and seamless integration with colleges and universities, colleges and universities will also have good and evil people mixed up while expanding the enrollment. And most students are confused about the future, having no professional sense. They don't know what they really want to do, or they don't know what they can do, or they don't know what they are suitable for, or they don't even know what areas they are studying, etc. In addition to having a strong material warm power in university development, at the same time, it is necessary to inject the warm power of culture and humanistic concern for the development of the university. The students can feel the warmth at home, fully demonstrating that the school is a family with both temperature and power.

2) Insisting on spiritual values and calling for warm power in the era of economic marketization: In the era of economic marketization, people's successful wealth and value utilitarianism are becoming more and more serious. In the process of maximizing material interests, people can easily have moral decline and neglect the spiritual values, and universities are part of the social system. Some negative factors will spread to popular colleges and universities. The management model of "administrative leadership" and "stability overwhelming" has become more and more rigid. In dealing with the relationship between teachers and students and the interests of school development, the multiple conflicts such as "rule of law and rule of man", "fairness and efficiency", "ethics and morality", and "principles and emotions" often appear, lacking the ability of listening to the legitimate interests of teachers and students, neglecting the rights and humanistic concern for the teachers and students, and losing the "free, independent, critical" spirit. College administrators are accused by the public of "work anomie" and "emotional coldness", but the reality tells people that colleges and universities pursue humanity and rationality and advocate science and research. If college education deviates from the human pursuit of "human being purpose", the goal of educating people and the pursuit of value deviates, contrary to the essence of education, the college students trained are also immoral, unreasonable and improper. Therefore, a child who grows up in a normal environment will not become a college student "Ma Jiajue" who killed his four roommates with a cold knife because of playing cards, [10] nor become "Lin Senhao", a medical graduate of Fudan University who poisoned roommate Huang Yang because of being jealous and disregarding for life, [11] nor become "Wu Xieyu", the brilliant student of Peking University who killed his mother [12]. Although similar extreme events are cases and do not represent current college students, the Chinese Mental Health Association College Student Psychological Counseling Committee has conducted a survey that should not be underestimated. The survey shows that nearly $40 \%$ of university freshmen and more than $50 \%$ of graduates have different psychological problems, among which "interpersonal communication, learning pressure, employment pressure and emotional dilemma" are the most prominent secret troubles. Nowadays, all kinds of competitive pressures are even greater. If people can't care for and promptly solve these problems and let them grow viciously, there may be another person who is distorted like the "Ma Jiajue who kills roommates", "Linsonhao who poisons" and "Wu Xieyu who kills the mother".

Therefore, a professor of Medical School of Fudan University learned that after "Lin Senhao who poisoned", he wrote in the window of a certain laboratory on campus that "it's the same root, why is it too urgent to fry?" It has created the indifference of criminal suspects to the lives of others. And is it not a universal questioning of society? When people hate these cruel behaviors and are shocked by these distorted minds, it is necessary to think whether families, schools, and society value their mental health as well as academic performance and famous school and become their "shepherd" in their primary, secondary, and university education.

Therefore, General Secretary Xi Jinping pointed out at the symposium of teachers of school ideological and political theory that the youth stage is the jointing and booting stage of life, and it is most necessary to guide and cultivate it carefully. It is necessary to bury the seeds of truth, goodness and beauty for the students, and guide students to buckle the first granule button in life [9]. 
3) Calling for warm power in the era of multicultural symbiosis in colleges and universities: In the social ecological environment where multicultural symbiosis and diverse groups coexist, diversified survival and diversified development have become the basic characteristics of social groups. For this reason, colleges and universities also face the situation of diversified times. From the family background, there are "official second generation", "rich second generation" and "second generation of agriculture" and "second generation of poor". From the perspective of birth, there are 00s, 90s and 80s. From the perspective of the academic performance, there are excellent students, middlelevel students and students with learning difficulties. From the perspective of the school identity, there are class cadres, party members, volunteers and members of the community. From the perspective of the maturity of mentality, there are activists, radicals, passives and mentally handicapped. From the perspective of the value, there are utilitarian, hedonist, homeopathic, cynical, guerrilla, philosopher, and entrant. Different groups have gathered in colleges and universities in a complex way, forming a huge youth community embedded in various organizational relationships, and weaving into a complex social network. Various groups work and coordinate with each other, exchange and cooperate with each other, and compete with each other for symbiosis. Therefore, the maintenance and development of these complex group relationships requires the constraints and norms of interest mechanisms, and more requires the guidance and construction of moral values. To this end, as the "public" organization connecting "people" naturally, the implication of ethics in colleges and universities is natural. Therefore, in management, when colleges and universities follow the rules and regulations of the school to manage students, they should take the "ethical concept" to care for the "healthy growth" of students, and control and prevent the behavior of "ethical misconduct", use "ethical value" to enrich "the valuables of educating people", build a "warm culture" of humanistic care-oriented campus, enrich the spiritual life of students, and advocate an experiential model of student ethics construction, making the college education reasonable and governance harmonious after the expansion and enrollment.

\section{IMPROVING THE STRATEGY OF WARM POWER OF COLLEGES AND UNIVERSITIES}

\section{A. Consolidating the Hard Power and Soft Power of Colleges and Universities}

Once the warm power of colleges and universities left the hard power and soft power, it has become the passive water or wood without roots, and it will not be "warm" in any case. For example, the warm power of China is now stronger and stronger, which is inseparable from the support of the country's growing hard power. On the other hand, as the country's warm power is growing stronger, it will promote the country's hard power to be stronger. In the same way, the improvement of personal warm power requires the improvement of individual legal, moral, and civilized literacy. At the same time, the continuous improvement of personal warm power will also drive more and more people's quality. As the saying goes, loving a person starts from the value of the face, ends because of the talent, and will be loyal because of the character. This is the best explanation of the personal warm power. The stronger the warm power is, the more people who participate in the cohesion of this warm power will be; the more people gather this warm power, the greater the effect of warm power, and the relationship between warm power and hard power and soft power is mutually inherited and mutually reinforcing.

\section{B. Talent Is the Key for Enhancing the Warm Power of Colleges and Universities}

People are the most active factor in productivity and the core strength of the development of colleges and universities. Promoting the warm power of colleges and universities, talent is the key. What kind of talent is most popular and favored by teachers and students? It's easy to think of someone with a smile on his or her lips. However, some scholars have said that the students are most annoyed by the "teachers" who have a very good attitude but have no knowledge. In this regard, the author deeply agrees with this opinion. How can the teachers with super good attitude and no hard power be qualified for the college work? How can the colleges and universities improve the warm power? The individual's warm power is more from the improvement of his own cultural literacy and the good moral character of his life, and there has the theory of "educational plan being teacher-oriented", "people with high-level knowledge being a teacher", and "people with high virtue being a model". Therefore, against the background of "double first-class" construction, the national "talent war" has kicked off. To achieve long-term development strategic goals, colleges and universities must work hard to retain talents. Colleges and universities should have the wisdom of knowing talents, the sincerity of loving talents, and the courage to use talents to create the commanding heights of talents, and attract outstanding talents from all walks of life in China and foreign countries to colleges and universities. According to the author's understanding, in order to retain talents and attract talents, Lanzhou University implements the "highlevel talents" income guarantee mechanism and the "highlevel talents medical care" system, and gives a tilt in the aspects of talents' work and living treatment. Professor $\mathrm{Wu}$ Wangsuo of the university called the implementation of the talent security system a "warm heart" project. It is both warm-hearted and comfortable, and it is also necessary to reassure them. The "guests" in the distance happily stay, and the locals as the owners feel comfortable. People can show their talents, have a stage, play a role, have a platform, and make achievements on the podium, truly creating a good talent environment of "pleasing the neighbors and attracting the strangers" [13].

\section{Improving the Warm Power of Colleges and Universities}

Jack C. Francis said, "You can buy a person's time. You can hire a person to a fixed job. You can buy technical 
operations on time or on a daily basis. However, you can't buy enthusiasm; you can't buy creativity; and you can't buy the wholehearted investment. You have to try to fight for these [14]."

Jack Francis tells people that money is important, and feelings and money also have its power. In the context of the "double first-class" construction, the "talent war" has kicked off. How to recruit talents and how to retain talents is the only way for the development of colleges and universities.

On December 29, 2016, President Luo Jun of Zhongshan University made a speech at the Talent Work Conference, "The Road to Talent Development is the Only Way for School Development" [15] pointed out: "Pure salary (money) can't attract talent, nor retain talents." At the same time, President Luo said sharply: "It is not possible to dig away people of Zhongshan University with wages. If they are entangled in wages, they should not come to Zhongshan University. Zhongshan University doesn't need people who want to move profitably. Zhongshan University wants people who associate their own development with the fate of Zhongshan University. Zhongshan University is a place with dreams. It depends on career, culture, pursuit, and dream to retain talents." Therefore, colleges and universities use material warm power (hard power) to attract people. At the same time, colleges and universities should fully create cultural warm power and make schools a collective with both strength and temperature, both tension and tenderness. Otherwise, who will do the best to work for the collective? It will inevitably lead to the faculty and staff who "yearn for the other campus", or "one performs one's function". They would transfer negative energy. For example, a president of the northwest university in 985 Project received such a letter from a student who was full of depression: "A teacher in class asked the reason why choose this college with more than 600 scores. Is the life choice wrong? [16]". Facing the chaos in the classroom teaching, can such teachers of "letter of the mouth" enhance the warm power of colleges and universities? On the contrary, only those teachers who love education and have a strong sense of responsibility will find ways to improve the warm power of the school, to teach with their heart, to solve the confuse, and to be able to withstand the "lonely" to study the subject, working for the school.

Therefore, in the face of the increasingly fierce competition for talents, it is difficult for universities to maintain quality and lasting competitiveness without attracting and retaining outstanding talents. To be innovative and to reform, the colleges and universities must have excellent talents and a strong team. In the face of the current embarrassing education problems, colleges and universities need to retain a large number of extremely talented people. How to truly "retain people by career, to retain people by treatment, to retain people with feelings" is worthy of the leaders to ponder. If colleges and universities only use the system to retain people, use contracts to retain people, and use power and interests to intimidate and keep people, the employees will be laid off or not be given files when they want to leave. This is a lack of wisdom and long-term vision. The behavior will inevitably lead to "no one stay". The outstanding talents will find another way out. Therefore, colleges and universities should encourage teachers to innovate and strive to provide teachers with a platform for self-worth, so that teachers can truly respect labor and respect talents. Only in this way can enhance cohesiveness and promote healthy and stable development of colleges and universities.

\section{Taking Students as the Subject and Improving the Warm Power of Colleges and Universities}

Against the background of human beings entering the era of humanistic economy, all aspects of people's life, study, work, and communication are based on the foundation of "human-oriented", following the care of "human nature" and striving for the manifestation of "humanity." To this end, the management of college students also urgently needs the guidance of "human-oriented, humanity and human nature", takes the "student-oriented" development approach, arouses the awakening of students' subjective consciousness, stimulates students' subjective motivation, respects and highlights the subjective initiative of students. Therefore, in the management, it is necessary to require university administrators to establish a management philosophy of "relying on students, believing students, facing students, respecting students, understanding students, and serving students" to maximize the initiative, creativity and life feature of students. The evaluation of student management performance should not only pay attention to the realization of management objectives, but also pay attention to the realization of students' educational goals, pay attention to the individualized growth of students and their own comprehensive development. The management of students should not only use traditional ideological education methods, but also adopt modern cultural management, and focus on goal incentives, role incentives, emotional incentives, trust incentives, self-motivation and cultural incentives. The goal and destination of student management is to promote the healthy growth of students' physical and mental health, and to cultivate an independent, distinct, diverse and qualified motherland builders and reliable successors, promoting the comprehensive development of college students' knowledge, virtue and emotions. However, judging from the current situation of student management in colleges and universities, the status of college students has not attracted enough attention, and they still stay in the weak position of "being managed". The main status of college students only stays at the level of slogans such as "for all students, and for all the things of students". However, these have not been implemented in the specific education practice. The traditional student management methods such as "management, control, and pressure" are still popular in the current work of college students. This kind of human requirements inconsistent with the human era should be abandoned and removed.

Therefore, for the management of students, it is necessary to carry out a revolution for the managers; the idea must be reformed; the method should be improved; and the traditional student management methods such as "management, control, and pressure" should be transformed into the management mode of "distribution service", that is, 
the combination of decentralization and management, the optimization of services, and the combination of management and service.

For example, Zhejiang University decentralized the evaluation of the initiative to the students, so that students can openly score according to the evaluation criteria. The teacher can't intervene in the students' vote. This initiative has been unanimously praised by students. A student at Zhejiang University said: "... in the evaluation of awards, students have learned fairness and justice."

\section{E. Cultivating Students in the Context of Good Learning Style and Improving Warm Power of Colleges and Universities}

The wind sneaked into the night and moistened things silently. Intangible education, such as moistening silently, deeply affects the formation of students' values. The ancients also said: "The peach and the plum do not speak, yet a path is born beneath them."

With the development of the times, the university has already been seamlessly connected with society. The hot spots in the society will soon become the core topic of campus discussion, and the social atmosphere will soon be scraped into the campus. The wind seems invisible and gradually has influences on human. Whether colleges and universities are fluent and direct, directly affects the formation of students' values, and whether they can buckle the first button of their lives.

Concern comes from the details, and warm heart comes from the little goodwill. For example, a canteen master of Beijing Normal University finds that a student only pays the cheapest dish every time. After that, the master will give the student more each time. It is only a small goodwill, and this detail is a work that the school tells the staff to pay attention to [16].

Another example: the male supervisors of dorm of the Renmin University of China are a group of big and tall "uncles". According to the changes of the weather, they carefully remind the students to pay attention to the body on the blackboard every day. When they see the students, they will take the initiative to talk with them. The students are in the caring atmosphere, and can learn the caring and dedication.

\section{CONCLUSION}

In summary, under the new trend of the new era, colleges and universities can grasp the trend of the times, and use culture to refine the "student's mind", achieving the effect of "cultivating people silently", "transforming the model from educating the body to the educating the will of the students, realizing the dual cultivation of "personality" and "humanity", and highlighting the spirit of scientific humanism. At the same time, colleges and universities should scientifically and rationally make the management work "effective", "orderly", "sentimental" and "righteous", carefully "care for the life of teachers and students, pay attention to the growth and attribution of teachers and students, and ensure the happy life of teachers and students". Then the campus is full of humanities concern, achieving the integration of "sense" and "governance", eliminating barriers and guards, creating a fair, just, harmonious and happy college environment, construct a positive and upward atmosphere, realizing the strategy of implementing warm power in colleges and universities, and injecting new vitality into the development of colleges and universities.

\section{REFERENCES}

[1] Wang Shanping. Using "warm power" thinking to response the "smart power" of the United States [J]. Leadership Science, 2013 (01): 4-7. (in Chinese)

[2] Zuo Junzhan. The spread of "warm power": a new strategic thinking that should be established in military external propaganda under the new media environment $[\mathrm{J}]$. Journal of Naval University of Engineering (Comprehensive Edition), 2014, 11 (01): 31-35. (in Chinese)

[3] Zuo Junzhan. Using "warm power" to spread and enhance the influence of military external communication $[\mathrm{J}]$. Journal of Nava University of Engineering (Comprehensive Edition), 2016, 13(04): 46-51. (in Chinese)

[4] Ling Jun. Comment on the "warm power" of China's diplomacy. Global Network [EB/OL]. [2019-01-8] http://opinion.huanqiu.com/opinion_world/201310/4472260.html?agt=15417.

[5] The heart of the people is the biggest politics. [EB/OL].[2019-02-15] http://www.sohu.com/a/208140640_400344.

[6] National statistical bulletin on education development in 1999 education statistical database - Chinese education [EB/OL].[2019 02-15]

http://www.edu.cn/zhong_guo_jiao_yu/tjsj/zhsj/jiao_yu_fa_zhan/200 603/t20060323_11625.shtml

[7] Latest statistics! 2018 big data of education business development [EB/OL].[2019-02-26]. http://www.sohu.com/a/297963310_440562.

[8] Fang Zhanhua. Re-understanding of the function of higher education against the background of social and economic development Martin Trot's criticism on the development stages of higher education [J]. Comparative Education Research, 2004(09): 11-16. (in Chinese)

[9] What kind of people should the universities cultivate? The general secretary gave a clear answer [EB/OL].[2019-02-28]. https://www.sohu.com/a/230259247_161260.

[10] The sentence of Ma Jiajue, who killed four roommates in Yunnan university, made the police present weep.[EB/OL].[2019-0512] ]http://bbs.tianya.cn/post-free-3345458-1.shtml

[11] From poisoning to death: Lin Senhao's thoughts[EB/OL].[2019-05 12]. http://news.ifeng.com/a/20151211/46632123_0.shtml.

[12] The hidden danger of Wu Xieyu killing mother started from high school, but Wu Xieyu grabbed the wrong straw.[EB/OL].[2019-0512]. http://www.sohu.com/a/313217008_100185290.[2019-05-12]

[13] Please the neighbors and attract the strangers: Lanzhou University implements "warming heart" project to attract high-level talents. [EB/OL].[2019-05-15]. https://baijiahao.baidu.com/s?id=1599138125753195709.

[14] Yang He. Research on teacher incentive mechanism in colleges and universities [D]. Dalian University of Technology, 2005. (in Chinese)

[15] Luo Jun, President of Zhongshan University, Speech at the school talent work conference 2017. [EB/OL].[2019-05-18]. http://www.gaokaodaohang.cn/article/1019/238580.html.

[16] The change of colleges and universities against the background of strict governance of the party. People's Network[EB/OL].[2019-0520]. http://fanfu.people.com.cn/n1/2019/0610/c64371-31127433.html

[17] Wen Keqin, Ren Jianxiong, Li Zhengzhong. Teaching management ethics in Tianjin [M]. Tianjin: Tianjin People's Publishing House, 1988: 13-14. (in Chinese) 